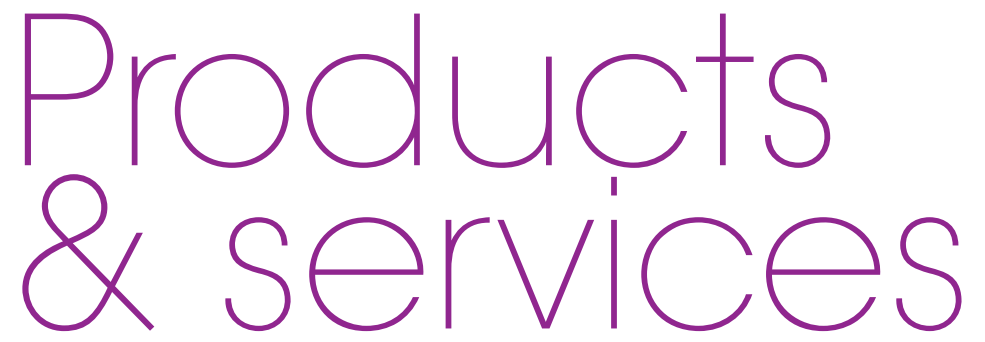

\title{
HELPING YOU IDENTIFY ACID WEAR
}

The results of ESCARCEL, the first and

largest pan-European Epidemiology

study to assess the prevalence and risk

factors for acid wear, offers unparalleled

insights into the condition

The study revealed just how

widespread acid wear is in young

adults across Europe, with one in three

exhibiting clinical signs. Of particular

concern is the evidence that this figure

is significantly higher in the UK.

ESCARCEL found that those aged

26-35 years were most affected by acid

wear, and exposed to what extent

conditions such as frequent heartburn

or acid reflux contribute.

Acid wear is an irreversible condition.

The best way to manage it is prevention

As identification of the early clinical

signs is the first step in helping to

protect patients from further damage,

the BEWE (basic erosive wear

examination) tool can help support

your understanding. Developed with Professor David Bartlett, Head of Prosthodontics from King's College London Dental Institute, the tool is split into three simple steps which can help you to assess patients' level of risk and ultimately aid your treatment decision.

GSK has launched the Pronamel BEWE and acid wear mobile app to help support you in detecting acid wear. Use the simple app on-the-go as an easy reference guide for the background to the condition, the BEWE tool and tips for patient management. Download the app from the iTunes App Store now, just search 'bewe'

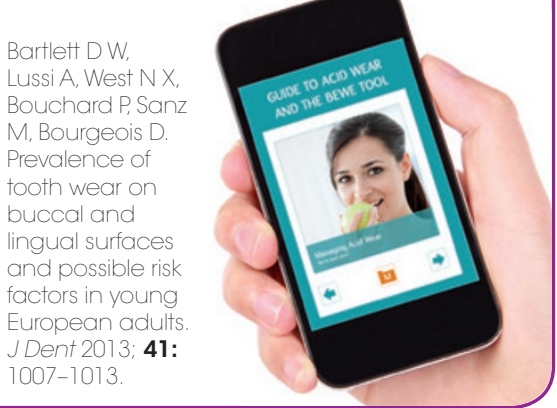

\section{TAKE ACTION AGAINST PERIODONTITIS}

New from oral healthcare specialist Curaprox is the perfect pocket minimiser for the treatment of chronic and aggressive periodontitis.

Adjusan combines the active ingredient doxycycline with a novel design for easy subgingival application, high tolerability and optimum efficiency. The effective and uncomplicated single administration is easily applied via the practical cylinder

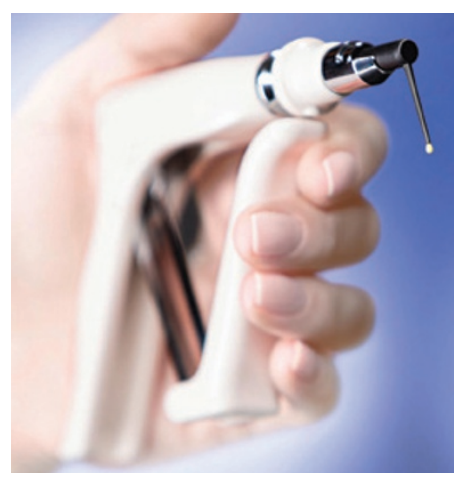

cartridge. The local antibiotic has the ability to kill key microorganisms whilst remaining safe for the patient.

Adjusan's most impressive characteristic is its innovative gel-like consistency. The initial flowable form allows you to reach the deep areas of the periodontal pocket, remaining in place as its viscosity increases in the aqueous environment. The active ingredient is released continuously over at least 12 days, enabling pocket depth to be reduced and attachment level enhanced.

For more information call 01480862084 or visit www. curaprox.co.uk

\section{CELEBRATING THREE DECADES OF TALKING POINTS}

GSK, manufacturers of
Aquafresh, Corsodyl,

Poligrip, Pronamel

and Sensodyne,

is inviting dental

professionals

to join them to

celebrate 30 years of

Talking Points in Dentistry.

The postgraduate lecture series first launched in 1985 and is open to all members of the dental team.

This year in celebration of the 30-year heritage of the programme we ask:

'Who will be the patient in 2045 and what will they want?' The lectures will reflect on the changes that have occurred in the dental industry over the last 30 years and how delivery of dental care will continue to evolve in the future.

Over the last 30 years more than 60 industry experts and professionals have delivered lectures to thousands of delegates. Many things have

evolved during that time, but the core focus has remained to provide topical and thought provoking content.

The lecture series will visit five venues across the UK during May:

- 12 May 2015 - Titanic Belfast

- 14 May 2015 - Dynamic Earth,

Edinburgh

- 18 May 2015 - National Motorcycle Museum, Solihull

- 20 May 2015 - National Museum, Cardiff

- 27 May 2015 - Royal Institute, London.

To book your place at your nearest venue simply visit www. gsk-dentalprofessionals.co.uk. Tickets are allocated on a first come, first served basis and limited to a total of six per practice, so book now!

If you would like to promote your products or services direct to the dental industry in BDJ Team, call Andy May on 02078434785 or emaila.may@nature.com. 